\title{
Development and Validation of an Instrument to Measure Teachers' Professional Agency during Curriculum Reform and Its Underlying Structure
}

\author{
Lawsha Mohamed \\ Kulliyyah of Education, \\ International Islamic University Malaysia \\ Kuala Lumpur \\ lawshaa@gmail.com
}

\author{
Tunku Badariah Binti Tunku Ahmad \\ Kulliyyah of Education, \\ International Islamic University Malaysia \\ Kuala Lumpur \\ tbadariah@iium.edu.my
}

\begin{abstract}
The purpose of this study was to develop and validate an effective instrument to measure teachers' professional agency and its underlying factors. Of major concern was the appropriateness of the items and the underlying structure of teacher agency. One hundred and fourteen $(\mathrm{N}=114)$ teachers from three primary schools in the Maldives filled out a teacher agency questionnaire. The validity and reliability of the instrument were tested using exploratory factor analysis and reliability analysis. Ninety-four items were developed in the initial item pool based on Priestley et al.'s (2015) ecological model of teachers' professional agency. An exploratory factor analysis extracted nine factors from the 94-item instrument on teacher agency, which altogether explained $76.37 \%$ of the variance in the pattern of relationships among the items. All the nine factors had high reliabilities with Cronbach's alphas greater than .791. Fifty-three items remained in the final questionnaire after deleting items with cross-loadings on multiple factors and loadings below .50. Hence, this study validated a ninefactor structure that represented the underlying dimensions of teachers' professional agency. This instrument could be used to gain a better understanding of the factors influencing teachers' professional agency during a curriculum reform.
\end{abstract}

Keywords: Professional agency, teacher agency, curriculum reform, collegial leadership, academic press, construct validation

\section{INTRODUCTION}

In any curriculum reform, teachers' professional agency is crucial to its success. Over the past decades, professional agency has become a focus of international research in the fields of teaching and teacher education (Ryder, Lidar, Lundqvist \& Östman, 2018; Pantić, 2017; Tao \& Gao, 2017; Kayi-Aydar, 2015; Vähäsantanen, 2015; Lipponen \& Kumpulainen, 2011). Professional agency refers to the notion that professionals such as teachers have the power to act, affect matters, make decisions and choices, and take stances, in relation to their work and professional identities (Vähäsantanen, 2015). In research, the terms "teacher agency" and "teachers' professional agency" have been used interchangeably to refer to teachers' active contribution to shape their work and its condition for overall quality of education (Biesta, Priestley \& Robinson, 2015).

Teachers are expected to exercise their professional agency in implementing a new curriculum (Priestley, Biesta \& Robinson, 2015) and redesigning curricula (Rogers \& Wetzel, 2013). Teachers use policy as a tool to adapt classroom instruction (Stillman \& Anderson, 2015) and curriculum goals and expectations to justify their adoption of innovative classroom 
activities and methods (Schwisfurth, 2006). Teachers with such abilities purposefully and skillfully draw on their agency to shape the curriculum, take control of their work, and strategically transform and refine their teaching.

The literature on the manifestations of teachers' professional agency points to several factors that underpin these actions. Emirbayer and Mische (1998) assert that agency does not come from nowhere, but builds upon three factors: one's past achievements, orientations towards the future, and engagement with the present. So, when studying the factors that influence and contribute to teachers' professional agency, these three aspects need to be considered. The first aspect, teachers' past achievements, is characterized by the features that developed from an interaction of factors in the past, namely factors such as personal capacity and beliefs (Priestley et al., 2015). Personal capacity refers to teachers' skills and knowledge about teaching which they acquired in the past that currently contribute to their actions and decision making in the present. For instance, a teacher who has the necessary skills and knowledge of teaching will have the confidence to critically judge and deal with dilemmas and challenges presently surfacing in the classroom. Teachers' beliefs about their role as teacher, facilitator and guide, and their capability to conduct new activities and respond to curricular changes are a major contributing factor to their professional agency. For example, teachers with high self-efficacy beliefs about their capability to conduct new activities in the classroom will be more confident in conducting such activities than those with less self-efficacy. Teachers' professional and self-efficacy beliefs guide them to become the sort of active, professional agents who exercise their agency. In the case of planning and developing new teaching materials, these teachers will actively give their ideas and contribute in accordance to their capacity and beliefs.

The second aspect that influences agency is the intention to bring about a future that is different from the present and past (Priestley et al., 2015). The orientation towards the future includes teachers' aspirations and motivation about their work and future goals. For instance, a teacher who aspires to be an influential teacher in school and in students' lives, would voice out his/her opinion and exert his/her power in problematic situations. The teacher would give his/her suggestions regarding activities, resources and materials that make a difference in learning as he/she wants to be an effective contributor. Similarly, a teacher who wants to make an impact on students' conduct would interfere and give his/her opinions when students are not behaving well.

Research The third aspect that influences agency is engagement with the present; this aspect is important because agency can be acted out in the present and depends on present circumstances (Priestley et al., 2015). Engagement with the present is influenced by the school climate which must foster a positive learning community where teachers can share ideas and feel comfortable about sharing experiences (Aldridge \& Fraser, 2015). According to Hoy, Hannum and Tschannen-Moran (1998), a healthy and open school climate should have specific features. One such feature is Collegial Leadership, which refers to the relationship between teachers and the principal. A school climate in which teachers feel the support of the principal tends to be more open and accepting of teachers' contributions towards the betterment of the school. Another feature is teachers' affiliation, i.e. the relationship teachers have with other teachers. The extent to which teachers can obtain assistance, advice and encouragement and feel accepted by their colleagues influence their practices in the school. Academic press is another feature of a healthy climate. It refers to the extent to which the school is driven by a quest for excellence. It indicates how well teachers and administrators set an achievement tone that is serious, orderly, and focused on academics. Working in a healthy and professional school climate allows teachers to exercise their professional agency. It leads to more responsible involvement in their work with students, thereby facilitating school development 
(Edwards, 2015; Pyhältö, Pietarinen, \& Soini, 2013).

Calls to understand the nature of teachers' professional agency and to develop it in the stream of change are common in policies and research worldwide (Pantić, 2015; Vähäsantanen, 2015). The focus of such research is on clarifying the meaning of teachers' professional agency, the ways in which professional agency is manifested during reform, and conditions supportive of such agentic behaviour (Pantić, 2015). Literature also suggests that teachers' professional agency is influenced by experiences from the past, orientations towards the future and engagement with the present. Past experiences such as teachers' personal capacity and teachers' beliefs contribute to the stands and judgments taken by the teachers. In addition, teachers' future aspirations and current school climate influence them to make stances and active involvement (Priestley et al., 2015). Hence to derive clear implications for policy makers, the interplay of factors that bring about teachers' professional agency needs to be understood well.

In the Maldives, a major curriculum reform is taking place. This reform was initiated to set a new national curriculum based on the concept of lifelong learning and employability in the progressive and challenging world (National Institute of Education, 2014). It is a complete reform of the previous curriculum with fundamental changes in philosophy, goals and principles, key competencies, structure and even content. In the guidelines to implement the new curriculum, teachers are given a very prominent role and much autonomy as the major and most influential medium who will ensure that the competencies outlined in the curriculum are well inculcated in students. Teachers are made accountable for the effective delivery of the curriculum and production of desired results. They are expected to plan, develop and deliver quality instruction that enables them to achieve curriculum outcomes (National Institute of Education, 2014). In short, these teachers are expected to exercise their professional agency in implementing the new curriculum. This, therefore, requires a thorough understanding of Maldivian teachers' professional agency and its development and manifestations in the current context of reform.

A comprehensive review of extant literature on teacher agency has identified some gaps that support the present research effort. The first gap identified is the scarcity of the literature on the underlying dimensions of and the factors influencing teachers' professional agency. None of the articles reviewed focused specifically on studying the factors that might influence teachers' agency in any of the contexts given, especially in the context of change and curriculum reform. Moreover, while reviewing the theories that might explain the manifestations of the construct and factors that contribute to teachers' professional agency, only a handful of theories could be relied on, among which was the ecological model used in the current study. The second gap identified in this review is the lack of teacher agency literature in the Maldivian context. Thus far, there is little understanding about Maldivian teachers' professional agency, and how it might operate in the present context of curricular reform. The third gap identified is the lack of quantitative research on the issue, especially in reference to educational reforms. Most of the research on the factors influencing professional agency tends to focus on qualitative data from which no statistical significance can be assumed. Furthermore, research has not been conducted to statistically identify or reject the factors that influence teachers' professional agency as proposed by Priestley et al. (2015). Hence, this study set as its aim to understand teachers' professional agency in the context of curriculum reform, and to further analyze their agentic behavior in the face of change.

\section{Objectives and Rationale of the Study}

This research is part of a larger study to explore the factors influencing teachers' professional 
agency in the context of curriculum reform in the Maldives. Research on Maldivian teachers' professional agency and factors influencing it is scarce. Prior to this study, there has not been any research conducted in this area. Thus, this is the first attempt to develop and validate an instrument assessing Maldivian teachers' professional agency, it underlying dimensions, and the factors influencing such agency.

For these reasons, the purpose of this study was to examine the factor structure of an instrument developed to measure Maldivian teachers' professional agency and the factors influencing it in the context of curriculum reform. The specific objectives of the study were:

1. To establish whether the items measuring various aspects of teachers' professional agency were appropriate and constituted an interpretable underlying factor structure; and

2. To determine the reliability and validity of the factor structure representing teachers' professional agency during a curriculum reform.

\section{Theoretical Framework}

The theoretical base used to form the conceptual framework of this study was taken from Emirbayer and Mische's (1998) chordal triad of agency (Figure 1). The theory suggests that the achievement of agency should be understood from three standpoints, namely the past, orientations towards the future, and engagement with the present. They refer to these three standpoints as the iterational, projective and practical-evaluative dimensions respectively.

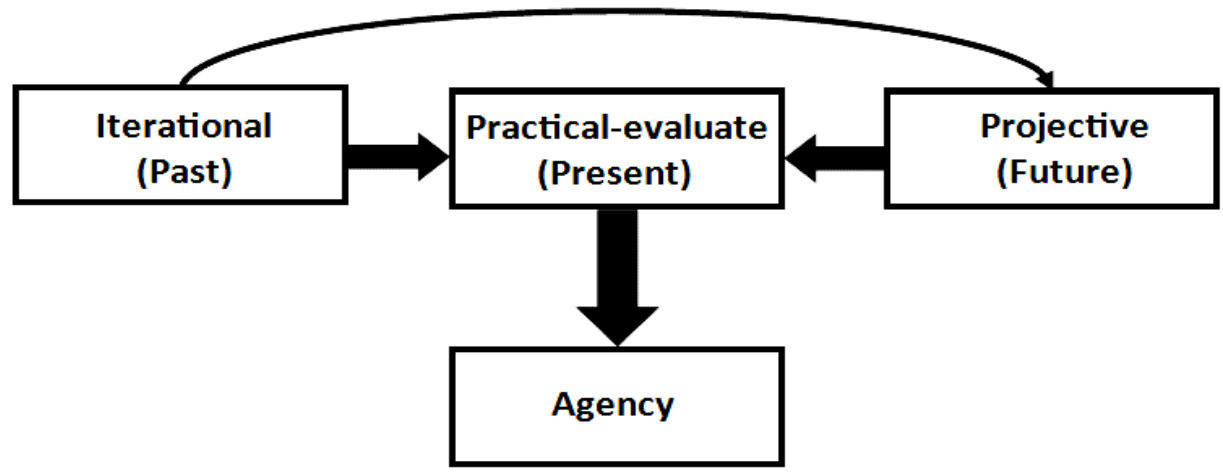

Figure 1. The Chordal Triad Theory of Agency (Priestley et al., 2015).

According to the ecological theory of agency (Priestley et al., 2015), each dimension contributes actively and positively to teacher agency. The iterational (past) dimension focuses on life stories and professional histories and how they influence present actions. The aspects include teachers' personal capacity (skills and knowledge), beliefs (professional and personal) and values. The practical-evaluative (present) dimension focuses on cultural, structural and material aspects. The projective (future) dimension focuses on aspirations that are linked to the intention to bring about a better future that is qualitatively and quantitatively different from the present and the past.

\section{Conceptual Framework}

Priestley et al. (2015) explained a number of iterational, projective and practical-evaluative aspects which contribute to teacher agency. The five major constructs of this study were chosen from these three dimensions and sub-dimensions as given by Priestley et al. (2015) in the 
Ecological perspective of teacher agency (Figure 2). Subsequently, some of the aspects were omitted to fit to the scope of the study, resulting in the proposed conceptual framework shown in Figure 3.

The two constructs, teachers' personal capacity and teachers' beliefs are iterational aspects (related to the past) that contribute to teacher agency. Each of them has two subconstructs. Perceived skills and knowledge are the sub-constructs of personal capacity, while beliefs are measured in professional and personal (self-efficacy) terms. Values are omitted from the current study's examination.

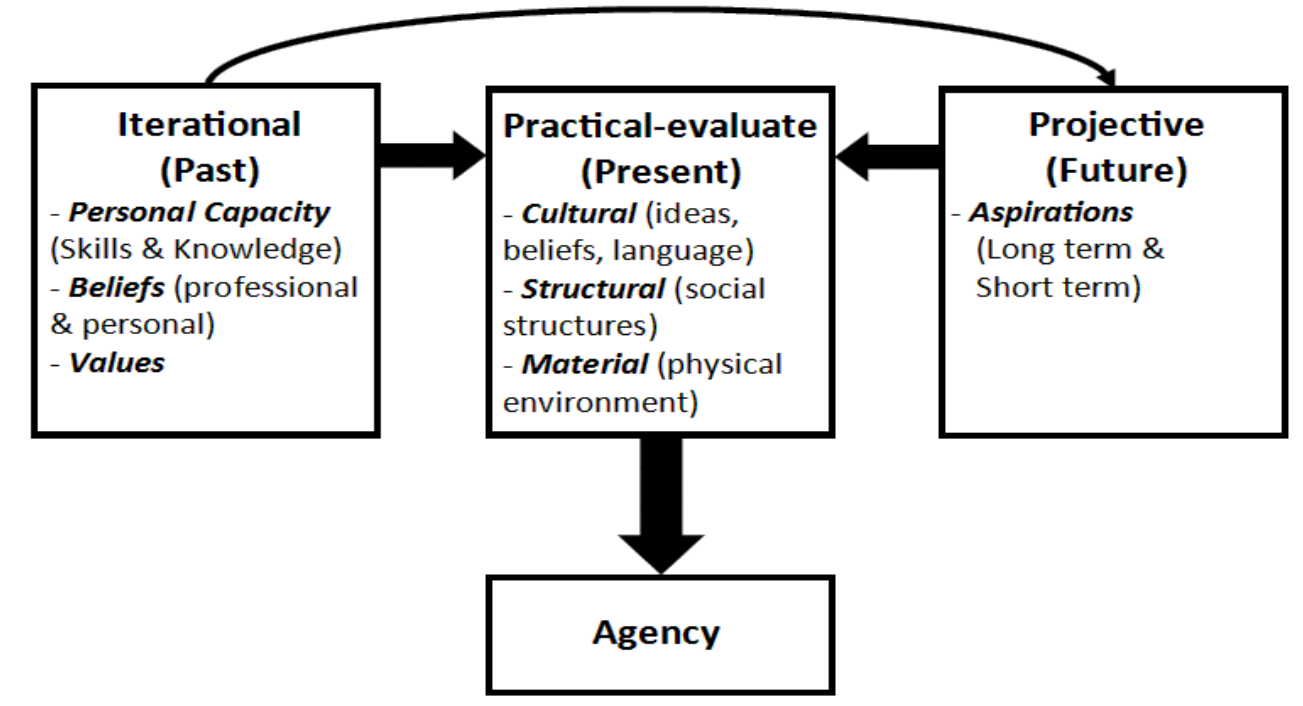

Figure 2. The Ecological Perspective of Teacher Agency (Priestley et al., 2015)

The third major construct, teachers' aspirations, is a projective dimension of agency as it is linked to the intention to bring about a future that is distinctively different from the present and the past (Priestley et al., 2015; Emirbayer \& Mische, 1998). The fourth major construct, school climate, constitutes the practical-evaluative dimension of agency as teachers' working environment involves activities and decisions making connected to the present situation. This construct has three subconstructs, i.e. teacher affiliation, collegial leadership and academic press. The fifth construct, professional agency, also involves the practical-evaluative dimension of agency as agency can only be "acted out" in the present (Priestley et al., 2015).

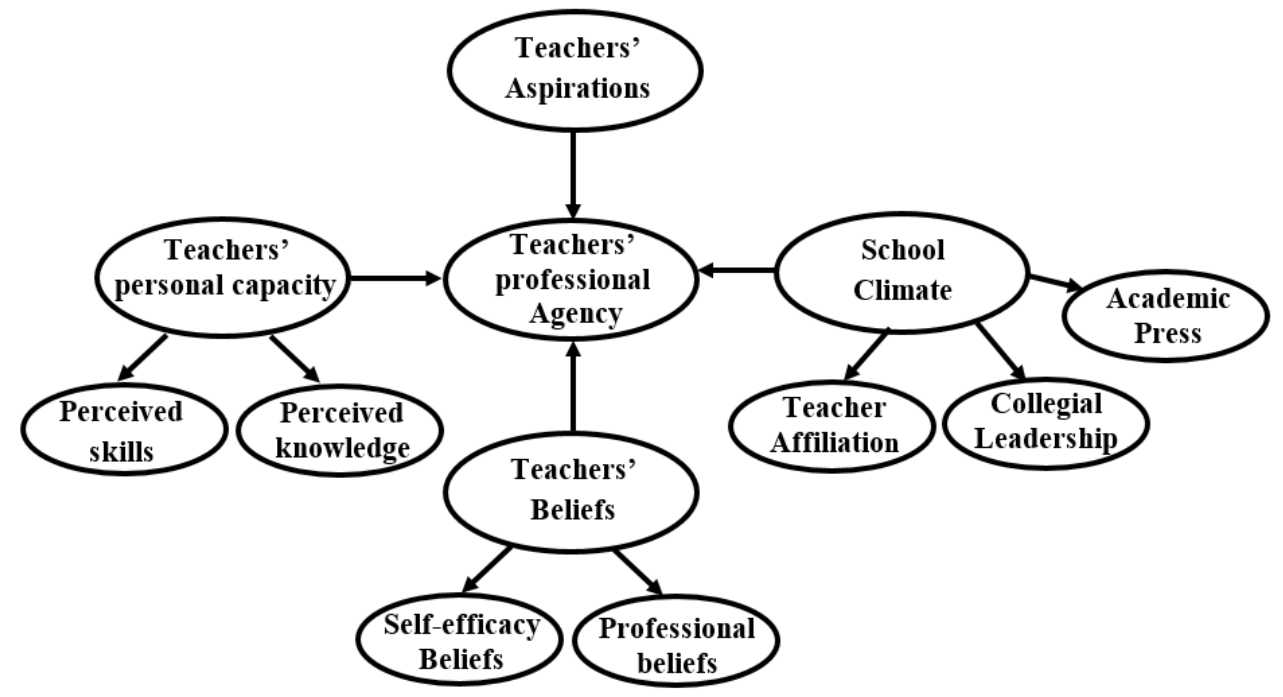

Figure 3. The conceptual framework of teachers' professional agency 


\section{METHODOLOGY}

\section{Research Design}

This quantitative study used the cross-sectional survey method to collect data to validate the instrument measuring the factors that underlie teachers' professional agency in the process of curriculum reform. Teachers from three schools situated in Male' City in the Maldives were selected to provide the data needed to examine and understand the teacher agency phenomenon as a major curriculum reform is occurring in these schools. All the schools selected have the following features: i) the teachers are primary school teachers; ii) all three are government schools; iii) all three schools are in the process of implementing the new curriculum; and iv) all are located in Male' City. Since the three schools are located in the same vicinity with similar facilities, infrastructure and probably culture, it is reasonable to expect the teachers to teach, act and behave in similar ways towards the reform.

\section{Respondents}

One hundred and fourteen $(\mathrm{N}=114)$ primary school teachers from three schools in Male' City filled out the questionnaire on teachers' professional agency. The sample was largely female (n $=72 ; 63.2 \%)$ and Maldivian $(\mathrm{n}=73 ; 64 \%)$. More than half had a bachelor's degree in education $(51.8 \% ; \mathrm{n}=59)$, while about one-fourth $(24.6 \% ; \mathrm{n}=28)$ had a master's degree or an associate degree in education. Half of the sample were well-experienced in teaching with $52.6 \%$ having more than 10 years in the field. Further information about the sample is given in Table 1.

Table 1

Demographic Characteristics of the Respondents $(\mathrm{N}=114)$

\begin{tabular}{lcc}
\hline Demographic Characteristics & $\mathrm{N}$ & $\%$ \\
\hline Gender & & \\
$\quad$ Male & 42 & 36.8 \\
$\quad$ Female & 72 & 63.2 \\
Nationality & & \\
$\quad$ Maldivian & 73 & 64 \\
$\quad$ Other & 41 & 36 \\
Teaching Qualification & & \\
$\quad$ Certificate level in teaching & 4 & 3.5 \\
$\quad$ Diploma in teaching & 23 & 20.2 \\
$\quad$ Bachelor's degree in education & 59 & 51.8 \\
$\quad$ Other (master's or associate degree) & 28 & 24.6 \\
Teaching Experience & & \\
0 - 3 years & 14 & 12.3 \\
3 - 6 years & 22 & 19.3 \\
6 - 9 years & 18 & 15.8 \\
10 or more years & 60 & 52.6 \\
\hline
\end{tabular}

\section{Survey Instrument}

From the review of literature and previous scales, 94 items were developed. These items represented the five constructs and sub-constructs of teacher agency identified in the conceptual framework. The items were reviewed by six content and measurement experts to further ensure 
the content validity of the item pool. Primarily, the experts were asked to evaluate the instrument by examining the representativeness of the items, that is, by deciding whether the items aligned with their operational definitions. The items were subsequently modified according to the experts' feedback. Table 2 gives further details about the questionnaire.

Table 2

The Teacher Agency Questionnaire

\begin{tabular}{|c|c|c|c|}
\hline $\begin{array}{c}\text { Construct \& } \\
\text { Definition }\end{array}$ & Subconstruct & $\begin{array}{l}\text { Total No } \\
\text { of Items }\end{array}$ & Sample Items \\
\hline \multirow{2}{*}{$\begin{array}{l}\text { Personal Capacity } \\
\text { [adapted from } \\
\text { Chong \& Cheah } \\
\text { (2009), and } \\
\text { Kereluik et al. } \\
\text { (2013)] }\end{array}$} & $\begin{array}{l}\text { Perceived } \\
\text { skills }\end{array}$ & 12 & $\begin{array}{l}\text { PS1 } \text { Communication skills } \\
\text { PS2 } \\
\text { Interpersonal skills } \\
\text { PS3 Classroom management skills } \\
\text { PS4 }\end{array}$ \\
\hline & $\begin{array}{l}\text { Perceived } \\
\text { knowledge }\end{array}$ & 9 & 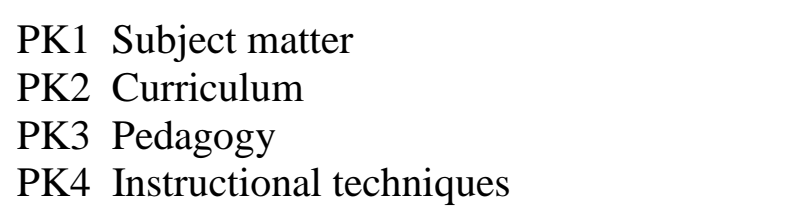 \\
\hline \multirow[t]{2}{*}{$\begin{array}{l}\text { Teachers' Beliefs } \\
\text { [adapted from } \\
\text { Harden \& Crosby } \\
(2000) ; \\
\text { McCormick et al. } \\
\text { (2006), Bandura } \\
(2006), \text { Schwarzer } \\
\text { et al. }(1999) \text { ]. }\end{array}$} & $\begin{array}{l}\text { Professional } \\
\text { beliefs }\end{array}$ & 12 & $\begin{array}{l}\text { PB1 Facilitating students' learning. } \\
\text { PB2 Establishing higher order thinking skills } \\
\text { in students. } \\
\text { PB3 Creating a meaningful learning } \\
\text { atmosphere for students inside and } \\
\text { outside the classroom. } \\
\text { PB4 Helping students solve their learning } \\
\text { problems. }\end{array}$ \\
\hline & $\begin{array}{l}\text { Self-efficacy } \\
\text { beliefs }\end{array}$ & 12 & $\begin{array}{l}\text { SE1 Teach new topics in the syllabus. } \\
\text { SE2 Carry out the new assessment procedure. } \\
\text { SE3 Teach to the outcomes. } \\
\text { SE4 Develop new teaching resources. }\end{array}$ \\
\hline \multirow[t]{3}{*}{$\begin{array}{l}\text { School Climate: } \\
\text { [adapted from } \\
\text { Hoy, Tarter \& } \\
\text { Kottkamp (1991), } \\
\text { Hoy et al. }(1998), \\
\text { Tschannen- } \\
\text { Moran, Parish and } \\
\text { Dipaola (2006)]. }\end{array}$} & $\begin{array}{l}\text { Teacher } \\
\text { affiliation }\end{array}$ & 10 & $\begin{array}{l}\text { TA1 Teachers exhibit friendliness to each } \\
\text { other. } \\
\text { TA2 There is a feeling of trust and confidence } \\
\text { among the staff. } \\
\text { TA3 Teachers in this school like each other. } \\
\text { TA4 Teachers accomplish their jobs with } \\
\text { enthusiasm. }\end{array}$ \\
\hline & $\begin{array}{l}\text { Collegial } \\
\text { Leadership }\end{array}$ & 9 & $\begin{array}{l}\text { CL1 The principal goes out of his/her way to } \\
\text { help teachers. } \\
\text { CL2 The principal looks out for personal } \\
\text { welfare of teachers. } \\
\text { CL3 The principal uses constructive criticism. } \\
\text { CL4 The principal listens to and accepts } \\
\text { teachers' suggestions. }\end{array}$ \\
\hline & $\begin{array}{l}\text { Academic } \\
\text { Press }\end{array}$ & 8 & $\begin{array}{l}\text { AP1 The school sets high standards for } \\
\text { academic performance. } \\
\text { AP2 Students respect others who get good } \\
\text { grades. }\end{array}$ \\
\hline
\end{tabular}


AP3 Academic achievement is recognized and acknowledged by the school.

AP4 Students try hard to improve on their previous work.

Teachers' Aspirations

[adapted from Veldman et al. (2017)]

7

ASP1 I wish to be an effective teacher in future.

ASP2 I aspire to be an influential teacher in future.

ASP3 I wish to be an effective contributor to my school.

ASP4 I wish to be a teacher who makes a difference in students' lives.

Teachers' Professional Agency [adapted from Tschannen-Moran et al. (2006), Mu et al. (2015), Liu et al. (2016), and Soini et al. (2015)].
13

PA1 I exercise my professional judgment in implementing the new curriculum.

PA2 I actively acquire parents' support to help with the education reforms.

PA3 I search and use various teaching and learning materials to deliver the new content

PA4 I try my best to expand my professional influence in the process of curricular change.

The items measuring the constructs were rated on a seven-point Likert scale. Perceived skills and perceived knowledge employed a seven-point Likert scale, where $1=$ None, $2=$ Very Poor, $3=$ Poor, $4=$ Moderate, $5=$ Adequate, $6=$ Good, $7=$ Very Good. All the other constructs employed a seven-point Likert scale of agreement, where $1=$ Strongly Disagree, $2=$ Disagree, 3= Slightly Disagree, $4=$ Neutral, $5=$ Slightly Agree, $6=$ Agree, $7=$ Strongly Agree .

\section{Data Collection and Analysis}

The main purpose of this research was to examine the appropriateness of the items and underlying structure of the constructs measuring teacher agency. With the approval of ministry of Education of Maldives, questionnaires were distributed to the primary grade teachers of the selected three schools. A total of 114 filled questionnaires were returned. An exploratory factor analysis, specifically principal axis factoring, was first conducted to evaluate the factor structure of the scale. Second, a reliability analysis was performed to test the internal consistency of the data derived from the preliminary set of items.

\section{Exploratory Factor Analysis (EFA)}

The data were entered into SPSS version 17 and analyzed to find the underlying factors of teacher agency, as well as the construct validity and reliability of the data. To find the factor structure of the scale, an Exploratory Factor Analysis (EFA) was conducted. According to Osborne (2015), the steps to follow when conducting an EFA include: (1) data cleaning; (2) deciding on extraction method to use; (3) deciding on how many factors to retain; (4) deciding on the rotation method; (5) interpreting the results; and (6) replicating or evaluating the robustness of the analysis. Hence, the data were first screened for missing values, disengaged data, and skewness and kurtosis to ensure they were good enough to run an EFA. 
The second step was to decide on the extraction method. Principal Axis Factoring (PAF) was chosen as the extraction method as it is judged to be the most appropriate method for identifying latent or underlying constructs that cannot be measured directly. In the third step, the Kaiser criterion was used in deciding the number of factors to be retained. The Kaiser criterion assumes that an eigenvalue greater than 1 is a good lower bound for expecting a factor to be meaningful. This is because eigenvalue represents the sum of the squared factor loadings and to get a value greater than 1, the items should have rather large factor loadings to square and sum (Kaiser, 1970). Since this study was based on a theory of teacher agency, it assumed the constructs of teacher agency to be theoretically correlated, thereby justifying the use of the Promax rotation technique. Being an oblique rotation (Thompson, 2004), Promax was expected to produce more theoretically accurate and reproducible solution from the teacher agency data as some correlation was expected among the factors (Osborne, 2015).

In the fifth step, Kaiser-Meyer-Olkin (KMO) measure of sampling adequacy test and Bartlets' test of Sphericity were analyzed to determine the construct validity of the items and factors, and to confirm that the data collected were appropriate. The KMO test was used to verify the sampling adequacy for the analysis, and Bartlett's Test of Sphericity was used to determine if the correlations among items were sufficiently large for EFA. Bartlett's Test of Sphericity should reach a statistical significance of less than .05 in order to conduct an EFA. Furthermore, the correlation matrix was checked to ensure moderate coefficients ( 0.5 to 0.84 ) (Osborne, 2015), communalities above 0.5 were ascertained to meet the sample size requirement (Worthington \& Whittaker, 2006), and the anti-image diagonal (above 0.5) was examined to ensure a correct interpretation of the results. The pattern matrix was analyzed to decide the factor structure and EFA results. Items that loaded on the wrong factors or crossloaded on multiple factors were deleted in a systematic order, and the EFA was re-performed until a clear factor solution was achieved. As a general criterion, item loadings need to exceed 0.5 on at least one factor and cross loaded items with a difference of 0.2 were maintained (Osborne, 2015).

\section{Reliability Analysis}

The reliability estimates of the constructs were computed using Cronbach's alpha. Acceptable alpha values should range from 0.70 to 0.95 (Tavakol \& Dennik, 2011) to show a good internal consistency, which means that the set of items tends to be closely related as a group.

\section{RESULTS AND DISCUSSION}

\section{Descriptive Statistics of the Factor Structure}

Table 3 shows the descriptive statistics, including the number of items, means and standard deviations of the nine extracted factors. The results show that all factors have high mean values, suggesting a gravitation towards agreement with or positive ratings of the proposed items. Among the nine factors that were extracted, Collegial Leadership $(\mathrm{M}=5.24)$ and Academic Press $(\mathrm{M}=5.85)$ have the lowest means, while Teachers' Aspirations $(\mathrm{M}=6.74)$ has the highest. 
Table 3

Descriptive Statistics of the Factor Structure $(\mathrm{N}=114)$

\begin{tabular}{llcc}
\hline \multicolumn{1}{c}{ Factors } & No of Items & Mean & $\begin{array}{c}\text { Standard } \\
\text { Deviation }\end{array}$ \\
\hline 1. Perceived Skills & 6 & 6.25 & .47 \\
2. Perceived Knowledge & 4 & 6.23 & .54 \\
3. Professional Beliefs & 6 & 6.57 & .61 \\
4. Self-Efficacy Beliefs & 4 & 6.39 & .69 \\
5. Teacher Affiliation & 7 & 6.13 & .70 \\
6. Collegial Leadership & 9 & 5.24 & 1.42 \\
7. Academic Press & 4 & 5.85 & .82 \\
8. Teachers' Aspirations & 5 & 6.74 & .46 \\
9. Teachers' Professional Agency & 8 & 6.34 & .75 \\
\hline
\end{tabular}

\section{Underlying Structure of Maldivian Teachers' Professional Agency}

The PAF with a Promax rotation run on the 94 teacher-agency items obtained a nine-factor structure consisting of 53 items. A total of 41 items were systematically deleted from the item pool in a series of PAFs run on the data. The KMO value of .783 , which was above the recommended threshold of 0.6 (Kaiser, 1974), verified the sampling adequacy for the analysis. Bartlett's test of sphericity, $\mathrm{x}^{2}(1378)=6321.42, \mathrm{p}<.001$, indicated that the correlations among the items were sufficiently large for the EFA. Nine factors had eigenvalues greater than 1 and were thus retained in the factor solution. The 53-item nine-factor structure explained $76.37 \%$ of the variance in the teacher agency data.

Although as general criteria, only items with loadings of at least 0.5 on at least one factor and cross-loaded items with a difference of 0.2 should be maintained, the latter rule was violated for the item on classroom management skills. Although the factor loading for classroom management skills was only .403 , the analysis maintained this item because its removal from the factor structure affected the factor loadings of other items in the construct. Furthermore, its inclusion did not influence the mean of its respective construct (Perceived skills). Table 4 shows the loadings and communalities of the extracted nine-factor structure that explains Maldivian teachers' professional agency.

Table 4

Loadings and Communalities of the Extracted Nine Factor Structure

\begin{tabular}{llcc}
\hline \multicolumn{1}{c}{ Item } & Loading & Communality \\
\hline Perceived Skills & & \\
PS3 & Classroom management skills & .403 & .343 \\
PS4 & Teaching skills & .500 & .407 \\
PS5 & Assessment skills & .614 & .577 \\
PS8 & Questioning skills & .584 & .541 \\
PS10 & Reflective skills & .616 & .395 \\
PS11 & Time management skills & .529 & .500 \\
Perceived Knowledge & & \\
PK1 $\quad$ Subject matter & & \\
PK2 & Curriculum & .688 & .566 \\
PK3 & Pedagogy & .936 & .802 \\
PK4 & Instructional techniques & .630 & .640 \\
& & .717 & .594
\end{tabular}




\section{Professional Beliefs}

$\begin{array}{llll}\text { PB7 } & \text { Acting as a role model. } & .877 & .824\end{array}$

$\begin{array}{llll}\text { PB8 Assessing students' work. } & .877 & .824\end{array}$

PB9 Planning the lessons. $\quad .877 \quad .866$

$\begin{array}{lll}\text { PB10 Organizing the study content. } & .894 & .654\end{array}$

PB11 Creating the study materials. $\quad .626 \quad .641$

$\begin{array}{lll}\text { PB12 Creating the resource materials. } & .739 & .790\end{array}$

Self-Efficacy Beliefs

$\begin{array}{llll}\text { SE4 Developing new teaching resources. } & .592 & .689\end{array}$

$\begin{array}{lll}\text { SE8 Getting the instructional materials and equipment I } & .680 & .680\end{array}$

$\begin{array}{llll}\text { SE9 Motivating students who show low interest in } & .587 & .830\end{array}$ school work.

$\begin{array}{llll}\text { SE10 Teaching new content to even the most difficult } & .652 & .739\end{array}$ students.

\section{Teacher Affiliation}

TA2 There is a feeling of trust and confidence among the staff.

TA3 Teachers in this school like each other.

TA4 Teachers accomplish their jobs with enthusiasm.

TA5 Teachers express pride in this school.

TA6 Teachers identify with the school.

TA8 Teachers respect the professional competence of

TA10 Teachers provide strong social support for their colleagues.

\section{Collegial Leadership}

CL1 The principal goes out of his/her way to help .73 teachers.

CL2 The principal looks out for personal welfare of

CL3 The principal uses constructive criticism.

CL4 The principal listens to and accepts teachers'

CL5 The principal compliments teachers.

CL6 The principal explores all sides of topics and

CL7 The principal puts suggestions made by the

CL8 The principal is willing to make changes.

CL9 The principal treats all teachers as his / her equal.

\section{Academic Press}

AP2 Students respect others who get good grades

AP4 Students try hard to improve on their previous

AP5 The learning environment is orderly and serious. grades. 


\section{Teachers' Aspirations}

ASP3 I wish to be an effective contributor to my school. $\quad .740$

ASP4 I wish to be a teacher who makes a difference in

ASP5 I wish to make an impact on students' conduct.

ASP6 I wish to be a role model to my students.

ASP7 I myself want to be a very involved teacher.

\section{Teachers' Professional Agency}

PA1 I exercise my professional judgment in implementing the new curriculum.

PA2 I actively acquire parents' support to help with the $\quad .783$ education reforms.

PA4 I try my best to expand my professional influence in the process of curricular change.

PA6 I make innovative suggestions to implement the new curriculum.

PA7 I voice out my opinions regarding syllabus content.

PA10 I welcome professional discussions with my colleagues regarding curriculum change.

PA11 I seek help from other teachers to support pedagogical changes.

PA12 I engage in collaborative inquiry in search of better methods of instruction.

The correlation matrix in Table 5 shows moderate correlations among the factors with the highest correlation observed between Factor 2 (Perceived Knowledge) and Factor 9 (Teachers' Professional Agency). The correlation indexes among the factors range from 0.011 to 0.493 , suggesting that multicollinearity is not an issue with the teacher agency dataset.

Table 5

Factor Correlation Matrix

\begin{tabular}{llllllllll}
\hline Factor & 1 & 2 & 3 & 4 & 5 & 6 & 7 & 8 & 9 \\
\hline 1 & 1.000 & .020 & -.012 & .448 & .011 & .044 & .450 & -.037 & .001 \\
2 & & 1.000 & .337 & .208 & .359 & .196 & .289 & .327 & .493 \\
3 & & & 1.000 & .336 & .458 & .198 & .184 & .306 & .472 \\
4 & & & & 1.000 & .242 & .149 & .462 & .091 & .266 \\
5 & & & & & 1.000 & .346 & .211 & .403 & .448 \\
6 & & & & & & 1.000 & .071 & .463 & .380 \\
7 & & & & & & & 1.000 & .014 & .152 \\
8 & & & & & & & & 1.000 & .305 \\
9 & & & & & & & & & 1.000 \\
\hline
\end{tabular}

The analysis yielded a nine-factor structure, where eight represented the underlying factors that might influence teachers' professional agency. Two factors, i.e. Perceived Skills and Perceived Knowledge characterized the main factor of Personal Capacity. Personal capacities of the individual who engages in agentic behaviour is one of the factors that will influence human agency (Oolbekkink-Marchand et al., 2017). Hence, the six items in the Perceived Skills construct and four items in the Perceived Knowledge construct might be a good representation of teachers' Personal Capacity. 
Similarly, the beliefs and values teachers hold about teaching and learning significantly influence the achievement of personal agency (Toom, Pyhältö \& Rust, 2015). The constructs of Professional Beliefs, consisting of six items, and Self-Efficacy Beliefs, consisting of four items, extracted in the scale can be used to measure the Teachers' Beliefs construct. According to Biesta et al. (2015), underlying beliefs about their personal and professional roles inform the judgments and choices made by teachers. Hence, professional and personal beliefs (including self-efficacy beliefs) play a vital role in the manifestations of teachers' professional agency.

The third main construct extracted in the analysis is School Climate. A study conducted by Soini et al. (2015) found that teachers' professional agency is more associated with a positive learning environment where learning is facilitated. Similar results were reported by Toom et al. (2017) which found that teachers' professional agency is related to a constructive school climate where teachers felt that their peers were supportive, and that they were treated in a respectful and equal manner. The three subconstructs identified in this study that measured School Climate are Teacher Affiliation (seven items), Collegial Leadership (nine items) and Academic Press (four items). One of the most widely used school climate instruments was developed by Hoy et al. (1991) which they further improved upon in a later study (Hoy et al., 1998) to include fortyfive items in a Likert questionnaire that measured six dimensions of school climate. Three of these six dimensions are reproduced in this study: Teacher Affiliation, Collegial Leadership and Academic Press.

The fourth construct extracted in the analysis is Teachers' Aspirations. It is one of the projective (future) dimensions of teacher agency where teachers' actions and decisions are influenced by their aspirations about the future. Aspirations can be seen as one particular category of beliefs where there is an orientation towards the future; teachers' aspirations, therefore, play a particular driving and motivating role in the achievement of agency (Biesta et al., 2015). This role was confirmed by the studies conducted by Veldman et al. (2017) and Nolan and Molla (2017).

Hence as suggested by Priestley et al.'s (2015) ecological model of teachers' professional agency, this study was able to extract eight factors, i.e., perceived skills, perceived knowledge, professional beliefs, self-efficacy beliefs, teacher affiliation, collegial leadership, academic press and teachers' aspirations, as the underlying structure of agentic behaviour (professional agency) among teachers.

\section{Item Analysis for Reliability}

The next step in the analysis was calculating the reliability of each of the nine teacher agency factors. In this study, the reliabilities of the constructs and subconstructs were estimated using the Cronbach's alpha as the internal consistency measure to indicate how well the items reflected a common underlying construct. According to Tavakol and Dennik (2011), an acceptable alpha value should range anywhere between 0.70 and 0.95 . Thus, based on this rule, all the nine factors of teacher agency have acceptable internal consistencies (Table 6).

Table 6

Internal Consistency Estimates of the Nine Teacher Agency Factors

\begin{tabular}{lcc}
\hline Construct & No of Items & Cronbach's alpha \\
\hline Perceived Skills & 6 & .791 \\
Perceived Knowledge & 4 & .855 \\
Professional Beliefs & 6 & .930 \\
Self-efficacy beliefs & 4 & .902
\end{tabular}




\begin{tabular}{lll} 
Teacher Affiliation & 7 & .923 \\
Collegial Leadership & 9 & .973 \\
Academic Press & 4 & .889 \\
Teachers' Aspirations & 5 & .904 \\
Teachers' Professional Agency & 8 & .941 \\
\hline
\end{tabular}

\section{CONCLUSION}

As a factor that hugely influences the success of curriculum reform, teachers' professional agency is little understood and little researched. This study attempted to reduce some of the ambiguity that surrounds the idea of professional agency and the underlying dimensions of teachers' agentic behaviour. Based on Priestley et al.'s (2015) ecological model of teacher agency, nine underlying dimensions were extracted from a PAF analysis of data provided by 114 Maldivian teachers directly involved in a ongoing curriculum reform. The nine factors of teachers' professional agency explained $76.37 \%$ of the variance in the pattern of relationships among the items. All the nine factors had high reliabilities with Cronbach's alpha indexes greater than .791. Fifty-three items, from an initial pool of 94 items, remained in the final teacher agency questionnaire after problematic items (i.e., those with cross-loadings on multiple factors and those with loadings below .5) were systematically deleted. Eight of the nine factors extracted represent the underlying dimensions of agency, while the ninth factor that was extracted constitutes the construct of professional agency itself as it operates in the context of curriculum reform in the Maldives. The first eight factors are postulated to be aspects that may influence Maldivian teachers' professional agency. They are perceived skills, perceived knowledge, professional beliefs, self-efficacy beliefs, teacher affiliation, collegial leadership, academic press and teachers' aspirations.

With the successful validation of a nine-construct professional agency instrument, the findings in sum contribute to the existing theory on teachers' agentic behaviour in the context of change by accentuating the important roles of such constructs as self-efficacy beliefs, teacher affiliation, collegial leadership and academic press. In terms of practicality, the instrument can be used to further understand the elements and circumstances that shape teachers' agentic behaviour and autonomy in the process of curriculum reform, specifically in the Maldives. However, due to the rather small sample size $(\mathrm{N}=114)$, the results should be read with caution. A further study involving more Maldivian schools and teachers should be undertaken to better understand the existing situation. 


\section{REFERENCES}

Afflerbach, P., Pearson, P. D., \& Paris, S. G. (2008). Clarifying differences between reading skills and reading strategies. The reading teacher, 61(5), 364-373.

Aldridge, J. M., \& Fraser, B. J. (2015). Teachers' views of their school climate and its relationship with teacher self-efficacy and job satisfaction. Learning Environments Research, 19(2), 291-307.doi:10.1007/s10984-015-9198-x

Bandura, A. (2006). Guide for constructing self-efficacy scales. In F. Pajares \& T. Urdan (Eds.). Self-efficacy beliefs of adolescents, (Vol. 5., pp. 307-337). Greenwich, CT: Information Age Publishing.

Biesta, G., Priestley, M., \& Robinson, S. (2015). The role of beliefs in teacher agency. Teachers and Teaching, 21(6), 624-640. doi.org/10.1080/13540602.2015.1044325

Chong, S., \& Cheah, H. (2009). A Values, Skills and Knowledge Framework for Initial Teacher Preparation Programmes. Australian Journal of Teacher Education, 34(3). https://doi.org/10.14221/ajte.2009v34n3.1

Edwards, A. (2015). Recognising and realising teachers' professional agency. Teachers and Teaching, 21(6), 779-784. https://doi.org/10.1080/13540602.2015.1044333

Emirbayer, M. \& Mische, A. (1998). What Is agency? The American Journal of Sociology, 103(4), 962-1023.

Harden, R.M. \& Crosby, J. (2000). AMEE Guide No 20: The Good Teacher is More than a Lecturer the Twelve Roles of the teacher, Medical Teacher, 22(4), 334-348.

Hoy, W., Tarter, C. J., \& Kottkamp, R. (1991). Open schools/ healthy schools. Newbury, CA: Sage.

Hoy, W., Hannum, J., \& Tschannen-Moran, M. (1998). Organizational climate and student achievement: A parsimonious view and longitudinal view. Journal of School Leadership, 8, 336-359.

Kaiser, H. F. (1970). A second generation little jiffy. Psychometrika, 35(4), 401-415. doi:10.1007/bf02291817

Kayi-Aydar, H. (2015). Teacher agency, positioning, and English language learners: Voices of pre-service classroom teachers. Teaching and Teacher Education, 45, 94-103. https://doi.org/10.1016/j.tate.2014.09.009

Kereluik, K., Mishra, P., Fahnoe, C., \& Terry, L. (2013). What Knowledge Is of Most Worth: Teacher Knowledge for 21st Century Learning. Journal of Digital Learning in Teacher Education, 29(4), 127-140.

Liu, S., Hallinger, P., \& Feng, D. (2016). Supporting the professional learning of teachers in China: Does principal leadership make a difference? Teaching and Teacher Education, 59, 79-91. DOI: 10.1016/j.tate.2016.05.023 
Lipponen, L., \& Kumpulainen, K. (2011). Acting as accountable authors: Creating interactional spaces for agency work in teacher education. Teaching and Teacher Education, 27(5), 812-819. https://doi.org/10.1016/j.tate.2011.01.001

McCormick, J., Ayres, P., \& Beechey, B. (2006). Teaching self-efficacy, stress and coping in a major curriculum reform. Journal of Educational Administration, 44, 53-70. http://dx.doi.org/10.1108/09578230610642656

Mu, G. M., Wang, Y., Wang, Z., Feng, Y., Deng, M. \& Liang, S. (2015): An Enquiry into the Professional Competence of Inclusive Education Teachers in Beijing: Attitudes, Knowledge, Skills, and Agency. International Journal of Disability, Development and Education, doi: 10.1080/1034912X.2015.1077934

National Institute of Education (2014). The national Curriculum Framework. Male': Maldives. Retrieved on 12 January 2019 from https://www.nie.edu.mv/index.php/en/nationalcurriculum

Nolan, A., \& Molla, T. (2017). Teacher confidence and professional capital. Teaching and Teacher Education, 62, 10-18. doi:10.1016/j.tate.2016.11.004

Oolbekkink-Marchand, H. W., Hadar, L. L., Smith, K., Helleve, I., \& Ulvik, M. (2017). Teachers' perceived professional space and their agency. Teaching and Teacher Education, 62, 37-46. doi:10.1016/j.tate.2016.11.005

Osborne, J. W. (2015). What is Rotating in Exploratory Factor Analysis?. Practical Assessment, Research \& Evaluation, 20(2), pp. 1-7

Pantić, N. (2015). A model for study of teacher agency for social justice. Teachers and Teaching, 21(6), 759-778. https://doi.org/10.1080/13540602.2015.1044332

Pantić, N. (2017). An exploratory study of teacher agency for social justice. Teaching and Teacher Education, 66, 219-230. https://doi.org/10.1016/j.tate.2017.04.008

Pyhältö, K., Pietarinen, J., \& Soini, T. (2013). Comprehensive school teachers' professional agency in large-scale educational change. Journal of Educational Change, 15(3), 303325. doi:10.1007/s 10833-013-9215-8

Rogers, R., \& Wetzel, M. M. (2013). Studying Agency in Literacy Teacher Education: A Layered Approach to Positive Discourse Analysis. Critical Inquiry in Language Studies, 10(1), 62-92. https://doi.org/10.1080/15427587.2013.753845

Priestley, M., Biesta, G.J.J. \& Robinson, S. (2015). Teacher agency: what is it and why does it matter? In R. Kneyber \& J. Evers (eds.), Flip the System: Changing Education from the Bottom Up. London: Routledge.

Ryder, J., Lidar, M., Lundqvist, E., \& Östman, L. (2018). Expressions of agency within complex policy structures: Science teachers' experiences of education policy reforms in Sweden. International Journal of Science Education, 40(5), 538-563. Doi:10.1080/09500693.2018.1435921

Schwarzer, R., Schmitz, G. \& Daytner, G. (1999). Teacher self-efficacy scale.Retrieved on 21 February 2019 from: http:www.ralfschwarzer.de 
Schweisfurth, M. (2006). Education for global citizenship: teacher agency and curricular structure in Ontario schools. Educational Review, 58(1), 41-50. doi:10.1080/00131910500352648

Soini, T., Pietarinen, J., Toom, A. \& Pyhältö. K. (2015) What contributes to first-year student teachers' sense of professional agency in the classroom? Teachers and Teaching: theory and practice, 21:6, 641-659, DOI: 10.1080/13540602.2015.1044326

Stillman, J., \& Anderson, L. (2015). From accommodation to appropriation: teaching, identity, and authorship in a tightly coupled policy context. Teachers and Teaching, 21(6), 720 744. doi:10.1080/13540602.2015.1044330

Tao, J., \& Gao, X. (2017). Teacher agency and identity commitment in curricular reform. Teaching and Teacher Education, 63, 346-355. https://doi.org/10.1016/j.tate.2017.01.010

Tavakol, M. and Dennick, R. (2011). Making Sense of Cronbach's alpha. International Journal of Medical Education, 2011: 253 - 255.

Thompson, B. (2004). Exploratory and confirmatory factor analysis: Understanding concepts and applications. Washington, DC: American Psychological Association.

Toom, A., Pyhältö, K., \& Rust, F. O. (2015). Teachers' professional agency in Contradictory times. Teachers and Teaching, 21(6), 615-623. doi:10.1080/13540602.2015.1044334

Tschannen-Moran, M., Parish, J., Dipaola, M. (2006). School climate: The interplay between interpersonal relationships and student achievement. Journal of School Leadership, $16(4), 386-415$.

Vähäsantanen, K. (2013). Vocational teachers' professional agency in the stream of change. Doctoral dissertation. University of Jyväskylä, Finland.

Vähäsantanen, K. (2015). Professional agency in the stream of change: Understanding educational change and teachers' professional identities. Teaching and Teacher Education, 47, 1-12. https://doi.org/10.1016/j.tate.2014.11.006

Veldman, I., Admiraal, W., Mainhard, T., Wubbels, T., \& van Tartwijk, J. (2017). Measuring teachers' interpersonal self-efficacy: relationship with realized interpersonal aspirations, classroom management efficacy and age. Social Psychology of Education, 20(2), 411-426. doi:10.1007/s11218-017-9374-1

Worthington, R., \& Whittaker, T. (2006). Scale development research: A content analysis and recommendations for best practices. Counseling Psychologist, 34, 806-838. 